\title{
Colorimetric detection of glucose and an assay for acetylcholinesterase with amine-terminated polydiacetylene vesicles
}

\author{
XUE WangXin, ZHANG DeQing*, ZHANG GuanXin \& ZHU DaoBen \\ Beijing National Laboratory for Molecular Sciences, Organic Solids Laboratory, Institute of Chemistry, Chinese Academy of Sciences, Beijing \\ 100190, China
}

Received January 26, 2011; accepted February 18, 2011; published online May 12, 2011

\begin{abstract}
The colorimetric response of amine-terminated polydiacetylene (PDA) vesicles was initially demonstrated by varying the $\mathrm{pH}$ of the solution. Convenient colorimetric methods to detect glucose and acetylcholinesterase (AChE) activity were successfully established using amine-terminated PDA vesicles by taking advantage of the following features: (1) the amine-terminated PDA vesicles undergo a colorimetric transition as the $\mathrm{pH}$ of the solution changes; (2) glucose can be oxidized to gluconic acid in the presence of glucose oxidase; and (3) AChE catalyzes the hydrolysis of acetylcholine to acetic acid. The visual detection of glucose levels and AChE activity showed good selectivity and acceptable sensitivity. The detection limit of glucose was $\sim 2.5 \mu \mathrm{mol} / \mathrm{L}$ and the level of AChE activity was assayed as low as $10.0 \mathrm{mU} / \mathrm{mL}$. Moreover, the amine-terminated PDA vesicles can be used for screening the activity of inhibitors against AChE.
\end{abstract}

polydiacetylene vesicles, glucose, glucose oxidase, acetylcholinesterase

Citation: Xue W X, Zhang D Q, Zhang G X, et al. Colorimetric detection of glucose and an assay for acetylcholinesterase with amine-terminated polydiacetylene vesicles. Chinese Sci Bull, 2011, 56: 1877-1883, doi: 10.1007/s11434-011-4505-0

Polydiacetylenes (PDAs) are usually prepared by light irradiation of self-assembled diacetylene monomers and purification is not required because no initiators or catalysts are used in the polymerization process [1-3]. A unique feature of PDAs is the existence of two phases that exhibit different absorptions; these are referred to as the "blue phase" and "red phase" [4,5]. For example, the blue PDA-vesicles that are synthesized from amphiphilic diacetylenes after UV light irradiation in aqueous solutions can be converted into the corresponding red phase in response to appropriate stimuli [6-15]. Using this feature of PDA-vesicles, a number of chemo-/biosensors have been reported in recent years [16-26]. For example, PDA-based detection of glucose was achieved by the ligand-induced conformational changes in hexokinase immobilized on a PDA monolayer [24]. Colorimetric DNA sensors have been constructed with PDA vesicles, in which probe DNA molecules were immobilized [24].

*Corresponding author (email: dqzhang@iccas.ac.cn)
Besides colorimetric sensing, elegant PDA-based fluorescent sensors have also been reported [25].

In this paper, we describe the colorimetric detection of glucose and acetylcholinesterase (AChE) activity using amine-terminated PDA vesicles from diacetylene 1 (Scheme 1) with a long alkyl chain and an amino group as the head-group [27-30]. The design rationale is schematically shown in Scheme 1 and explained as follows. (1) It is anticipated that the "blue-red" phase transition can also occur for the amine-terminated PDA vesicles by lowering the $\mathrm{pH}$ of the solution. For example, Kew et al. [9] have studied the $\mathrm{pH}$ response of carboxyl-terminated PDA vesicles. Here, coulombic repulsion between the adjacent ionized head groups after base-induced deprotonation is responsible for the conformational perturbation of the structure, leading to the blue-red colorimetric transition. (2) Glucose can be oxidized to gluconic acid in the presence of glucose oxidase (GOx) and as a result the $\mathrm{pH}$ value of the solution will decrease [31]. (3) Similarly, the hydrolysis of acetylcholine iodide catalyzed 


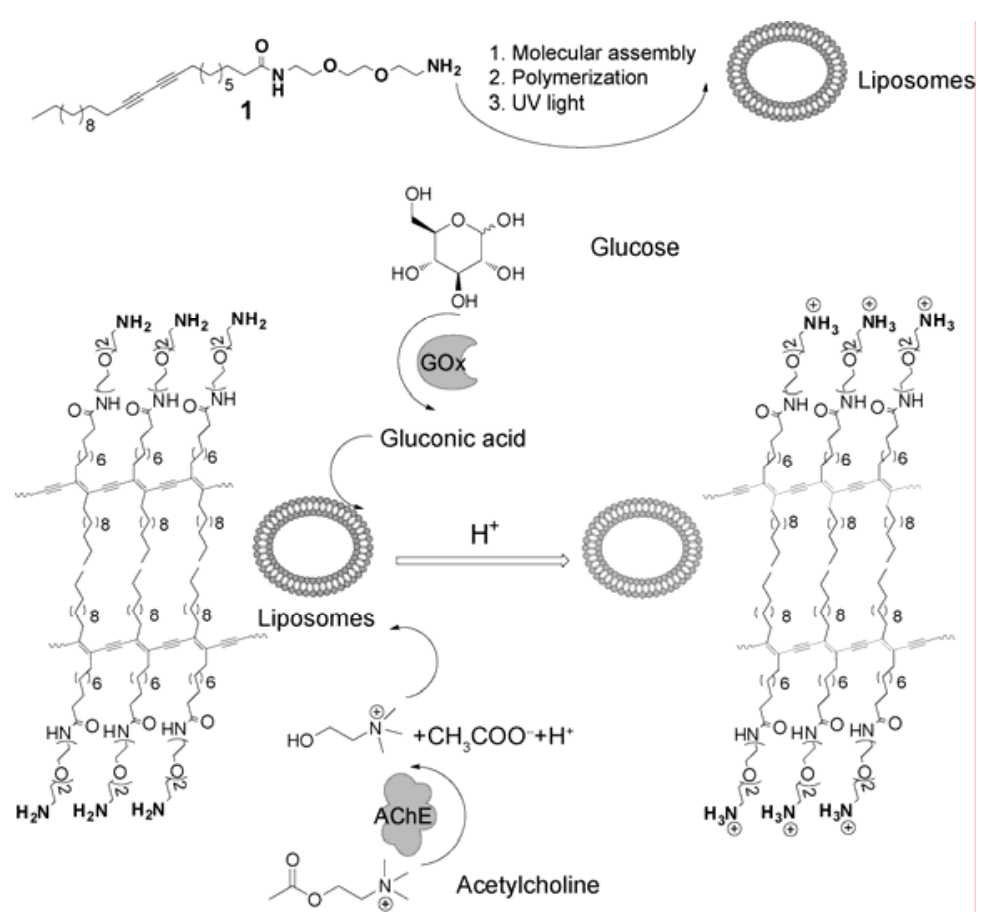

Scheme 1 Colorimetric detection of glucose and the assay for measuring acetylcholinesterase activity by combining the use of the amine-terminated polydiacetylene vesicles and the enzymatic reactions.

by AChE will lead to the generation of acetic acid and accordingly the solution will become acidic [32]. Therefore, it is possible to establish the colorimetric detection of glucose and the activity of AChE with amine-terminated PDA vesicles in the presence of GOx and acetylcholine iodide.

\section{Experimental section}

\subsection{Materials}

Acetylcholine iodide, glucose, fructose, mannose, galactose and maltose were obtained from Alfa-Aesar, whereas acetylcholinesterase and GOx from Electrophorus electricus were purchased from Sigma-Aldrich. The 10, 12-tricosadiynoic acid (98\%), $N$-hydroxysuccinimide (NHS) and 2,2'-(ethylenedioxy)diethylamine (EDEA) were purchased from SigmaAldrich. Ultrapure water was obtained using a Millipore filtration system. The amine-terminated diacetylene monomer $\mathbf{1}$ (10, 12-pentacosa-diynoic acid-2-2'(ethylenedioxy) bis (ethylamine)), was obtained by reacting PCDA-NHS ( $N$-hydroxysuccinimide ester of 10,12-pentac-osadiynoic acid) with an excess amount of EDEA (2,2'-(ethylene-dioxy) diethylamine) in methylene chloride, as previously described [27] . All experiments were carried out in ultra-high pure (UHP) water, except the $\mathrm{pH}$ responsiveness of the PDA absorption spectrum which was carried out in MES (2-( $N$ - morpholino) ethanesulfonic acid, $10.0 \mathrm{mmol} / \mathrm{L})$ buffer $(10.0 \mathrm{mmol} / \mathrm{L}$, MES = 2-( $N$-morpholino $)$ ethanesulfonic acid $)$.

\subsection{Apparatus}

Absorption spectra were measured on a U-3010 (Hitachi) instrument. All measurements were carried out at room temperature using cells with $1.0 \mathrm{~cm}$ optical path lengths.

\subsection{Preparation of vesicles}

Diacetylene monomer $\mathbf{1}$ was dissolved in chloroform in a test tube. The solvent was evaporated by a stream of $\mathrm{N}_{2}$ gas and deionized water was added to the test tube to give the desired concentration of $1\left(2.0 \mathrm{mmol} \mathrm{L}{ }^{-1}\right)$. The resulting suspension was sonicated for $5.0 \mathrm{~min}$ at $\sim 80^{\circ} \mathrm{C}$. After sonication, the solution was filtered to remove the aggregates with a $0.8-\mu \mathrm{m}$ filter and cooled at $4{ }^{\circ} \mathrm{C}$ overnight. PDA vesicles were prepared by UV light $\left(254 \mathrm{~nm}, 1.0 \mathrm{~mW} \mathrm{~cm}{ }^{-2}\right)$ irradiation of the solution for $90 \mathrm{~s}$.

To quantify the extent of the blue-red color transition for the PDA vesicles, the CR (the colorimetric response) was calculated using the following equation [33]:

$$
\mathrm{CR}(\%)=\left[\left(\mathrm{PB}_{0}-\mathrm{PB}_{1}\right) / \mathrm{PB}_{0}\right] \times 100
$$

where $\mathrm{PB}=A_{\text {blue }} /\left(A_{\text {blue }}+A_{\text {red }}\right), A_{\text {blue }}$ and $A_{\text {red }}$ are the absorbance values at $630 \mathrm{~nm}$ for the blue phase and $545 \mathrm{~nm}$ for the red phase, respectively. $\mathrm{PB}_{0}$ and $\mathrm{PB}_{1}$ refer to the blue/red ratios in the absence and presence of stimuli, respectively.

\section{Results and discussion}

\subsection{Preparation of the amine-terminated PDA vesicles and the CR to $\mathrm{pH}$ change}

The amine-terminated PDA vesicles were prepared from diacetylene 1 containing one amino group (Scheme 1) according to the reported procedure [27]. Briefly, diacetylene 
1 was dissolved in UHP water with the aid of ultrasonic treatment, and the aqueous solution was exposed to UV light $(254 \mathrm{~nm})$ for $90 \mathrm{~s}$. The as-prepared PDA vesicles were blue in color and exhibited strong absorptions around 630 $\mathrm{nm}$. The absorption spectra of the PDA vesicles were measured in MES buffer solutions of different $\mathrm{pH}$ values. As depicted in Figure 1(A), the absorption band around $630 \mathrm{~nm}$ decreased gradually, and concomitantly a new absorption band around $545 \mathrm{~nm}$ emerged. The intensity of the band at $545 \mathrm{~nm}$ increased gradually by decreasing the $\mathrm{pH}$ of the aqueous solutions. The color of the PDA vesicles gradually changed from blue to red as the $\mathrm{pH}$ was lowered. Moreover, the $\mathrm{CR}$ decreased almost linearly with the $\mathrm{pH}$ change in the aqueous solutions of the PDA vesicles (Figure 1(B)). Previous studies suggest that this spectral variation indicates the transformation of the blue-phase of PDA vesicles into the corresponding red-phase [27-30]. This structural transformation is probably induced by the protonation state of the amino groups of the vesicles in acidic solutions. Here, the electronic repulsion among the positively-charged head groups may alter the interactions of alkyl chains, and accordingly the conformation of the backbone of polydiacetylene would change.

\subsection{Colorimetric detection of glucose}

Glucose can be easily oxidized to generate gluconic acid
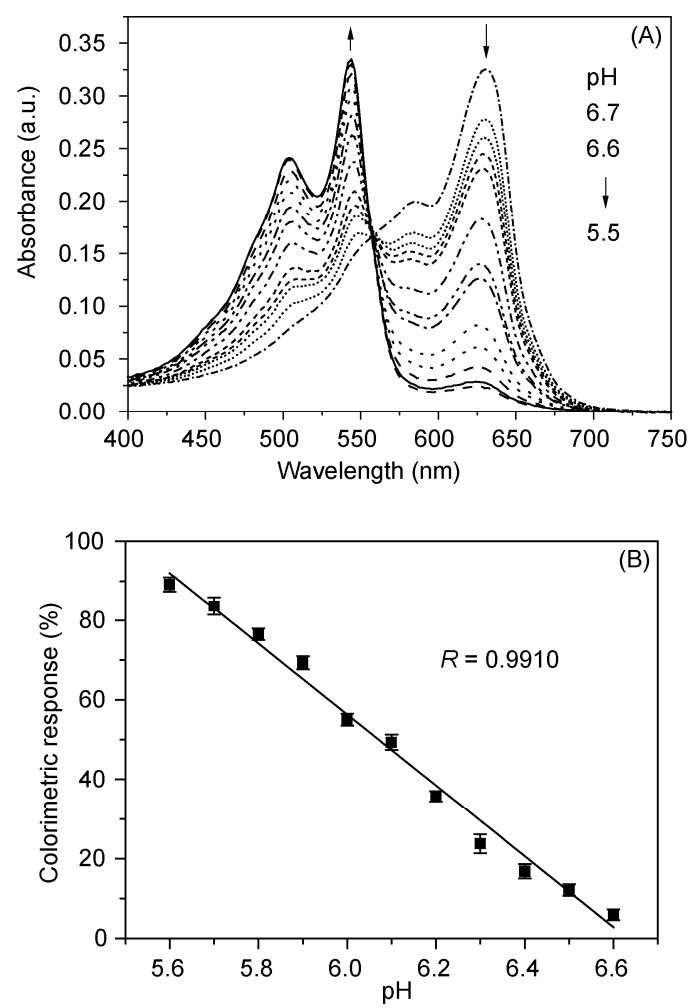

Figure 1 (A) The absorption spectra of the PDA-vesicles $(50.0 \mu \mathrm{mol} / \mathrm{L})$ in solutions of different $\mathrm{pH}$ values (6.7 to 5.5); (B) variation of the colorimetric response of the PDA-vesicles vs. the $\mathrm{pH}$. All experiments were carried out in MES buffer $(10 \mathrm{mmol} / \mathrm{L})$ at $25^{\circ} \mathrm{C}$. and $\mathrm{H}_{2} \mathrm{O}_{2}$ in the presence of GOx. Consequently, an absorption spectral change (the "blue-red" phase transition) should occur for the amine-terminated PDA vesicles following the addition of glucose in the presence of GOx. In Figure 2(A), the absorption signal around $630 \mathrm{~nm}$ gradually weakened in intensity and an absorption signal at $\sim 545 \mathrm{~nm}$ emerged, and the intensity of this absorption increased as the concentration of glucose increased (in the presence of GOx). Such absorption spectral variation was found to be dependent on the concentration of GOx in the solution. Figure S1 shows the plots of $\mathrm{CR}$, which reflects the absorption spectral variation for PDA vesicles vs. the reaction time (0-15 $\mathrm{min})$ for the PDA vesicle solutions containing glucose in the presence of different concentrations of GOx $(0.0,0.01,0.05$, 0.08 and $0.10 \mathrm{mg} / \mathrm{mL})$. Clearly, the changes in the $C R$ values were more remarkable for the vesicle solutions containing higher concentrations of GOx. However, as shown in Figure S2, the absorption change of the PDA vesicles was
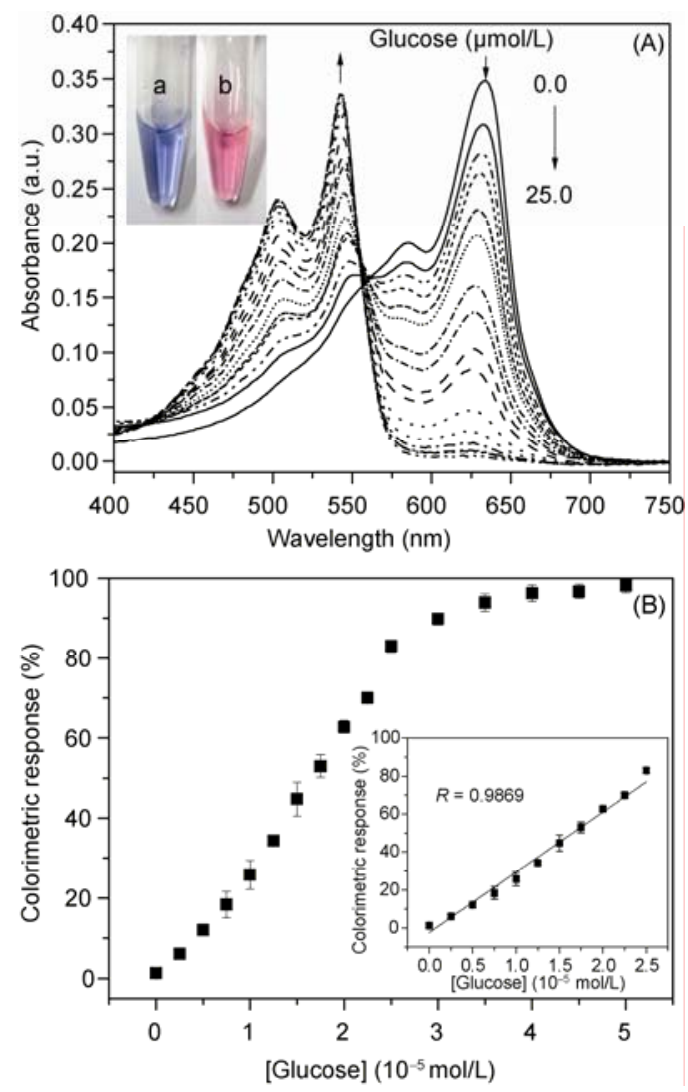

Figure 2 (A) The absorption spectra of a PDA vesicles solution (50.0 $\mu \mathrm{mol} / \mathrm{L})$ containing GOx $(0.1 \mathrm{mg} / \mathrm{mL})$ following the addition of different amounts of glucose (from 0 to $25.0 \mu \mathrm{mol} / \mathrm{L}$ ); each solution was incubated for $15 \mathrm{~min}$ at room temperature. The inset shows the color change for the PDA vesicles $(50.0 \mu \mathrm{mol} / \mathrm{L})$ containing GOx $(0.1 \mathrm{mg} / \mathrm{mL})$ in the absence (a) and presence (b) of glucose $(25.0 \mu \mathrm{mol} / \mathrm{L})$; photos were taken after incubation at $25^{\circ} \mathrm{C}$ for $15 \mathrm{~min}$. (B) The plot of the colorimetric response of the PDA vesicles $(50.0 \mu \mathrm{mol} / \mathrm{L})$ containing GOx $(0.1 \mathrm{mg} / \mathrm{mL}) v s$. the concentration of glucose. Each solution was incubated at room temperature for 15 min before recording the absorption spectrum. All the experiments were carried out in UHP water. 
negligible when either GOx or glucose was added.

To detect glucose with the amine-terminated PDA vesicles, the concentration of GOx must be fixed. Figure 2(A) shows the absorption spectra of the PDA vesicles (50.0 $\mu \mathrm{mol} / \mathrm{L})$ containing GOx $(0.1 \mathrm{mg} / \mathrm{mL})$ in the presence of different amounts of glucose after incubating at $25^{\circ} \mathrm{C}$ for 15 min. After the addition of glucose, the absorption around $630 \mathrm{~nm}$ started to decrease and that at $\sim 545 \mathrm{~nm}$ increased gradually. The plot of the corresponding CR vs. the concentration of glucose is presented in Figure 2(B). The CR increased linearly as the concentration of glucose increased (i.e. 0 to $25.0 \mu \mathrm{mol} / \mathrm{L}$ ), with a detection limit of $2.5 \mu \mathrm{mol} / \mathrm{L}$. The initial blue solution of the PDA vesicles $(50.0 \mu \mathrm{mol} / \mathrm{L})$ containing GOx $(0.1 \mathrm{mg} / \mathrm{mL})$ changed to the color red after $25.0 \mu \mathrm{mol} / \mathrm{L}$ of glucose was present and the solution was incubated for $15 \mathrm{~min}$ at $25^{\circ} \mathrm{C}$, as shown in the inset of Figure 2(A). Therefore, it can be concluded that naked-eye detection of glucose can be performed with the amineterminated PDA vesicles. Moreover, the detection limit and range can be modulated by adjusting the concentrations of the PDA vesicles and GOx.

Absorption spectra of the PDA vesicles in the presence of GOx after the addition of excess amounts of fructose, mannose, galactose and maltose were recorded to demonstrate the selectivity of the visible detection of glucose. Figure 3 shows the respective CR of the PDA vesicles in the presence of 1.0 equivalent (equiv.) of glucose and 10.0 equiv. of other saccharides. Clearly, significant colorimetric change was only detected for the sample that contained glucose. Thus, a simple, sensitive and selective colorimetric assay for glucose detection can be established by combining the use of the amine-terminated PDA vesicles and GOx.

It should be noted that various methods for glucose detection have been described. These include fluorescence $[34,35]$ and surface plasmon resonance spectroscopic

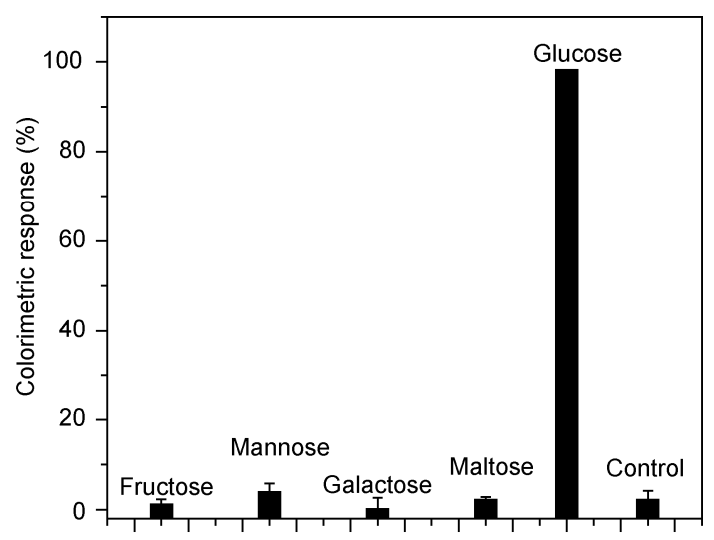

Figure 3 Variation in the colorimetric response for the PDA vesicles solution $(50 \mu \mathrm{mol} / \mathrm{L})$ containing GOx $(0.1 \mathrm{mg} / \mathrm{mL})$ following the addition of 1.0 equiv. of glucose and 10.0 equiv. of fructose/mannose/galactose/ maltose; each solution was incubated at room temperature for $15 \mathrm{~min}$. All experiments were carried out in UHP water. methods [36,37] as well as electrochemical approaches $[38,39]$. Nonetheless, the colorimetric detection of glucose based on amine-terminated PDA vesicles has the following advantages: (1) visible detection; (2) high selectivity; and (3) acceptable sensitivity.

\subsection{Colorimetric assay for $\mathrm{AChE}$ activity and inhibitor-screening}

Acetylcholine (ACh) is known to be a good substrate for $\mathrm{AChE}$, because it is easily hydrolyzed to choline and acetic acid by AChE. Thus, it is expected that the absorption spectrum of the amine-terminated PDA vesicles will change after mixing ACh with AChE. Figure 4(A) shows the absorption spectra of the PDA vesicles $(50 \mu \mathrm{mol} / \mathrm{L})$ in the presence of ACh $(40 \mu \mathrm{mol} / \mathrm{L})$ and $\mathrm{AChE}(40 \mathrm{mU} / \mathrm{mL})$ after various incubation times. The absorption around $630 \mathrm{~nm}$ gradually weakened, whereas the absorbance at $\sim 545 \mathrm{~nm}$ increased. Such spectral variation was more remarkable when the incubation time was increased. This is ascribed to the generation of acetic acid from the hydrolysis of ACh catalyzed by $\mathrm{AChE}$; as a result the amine head-groups of the PDA vesicles become protonated and accordingly the "bluephase" of PDA transforms into the corresponding "red-phase" [4]. In fact, obvious color changes occurred for the PDA vesicles containing ACh after the addition of AChE and further incubation ( Figure 4(B)). The initial vesicle solution $(50 \mu \mathrm{mol} / \mathrm{L})$ containing $\mathrm{ACh}(40 \mu \mathrm{mol} / \mathrm{L})$ was
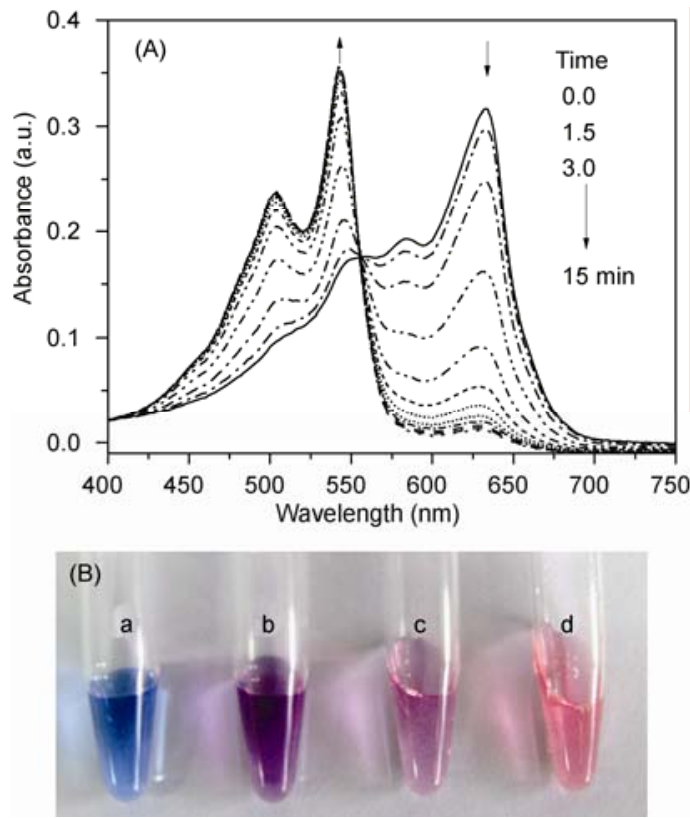

Figure 4 (A) Absorption spectra of PDA vesicle solutions $(50 \mu \mathrm{mol} / \mathrm{L})$ in the presence of ACh $(40 \mu \mathrm{mol} / \mathrm{L})$ and $\mathrm{AChE}(40 \mathrm{mU} / \mathrm{mL})$ following incubation for different times at room temperature. (B) Photos of the PDA vesicle solutions $(50 \mu \mathrm{mol} / \mathrm{L})$ and those after the addition of ACh (40 $\mu \mathrm{mol} / \mathrm{L}$ ) and different amounts of AChE: a, 0; b, 20; c, 40; d, $80 \mathrm{mU} / \mathrm{mL}$; each solution was incubated for $15 \mathrm{~min}$ at $25^{\circ} \mathrm{C}$. All experiments were carried out in UHP water. 
blue in color; however, the solution became red following the addition $\mathrm{AChE}(80 \mathrm{mU} / \mathrm{mL})$ and incubated at $25^{\circ} \mathrm{C}$ for 15 min (Figure 4(B)-d). If lower amounts of $\mathrm{AChE}$ were added, the contrast in color change was not as apparent, but it was distinguishable as shown in Figure 4(B)-b and c, for which the concentrations of AChE in the solutions were 20 and $40 \mathrm{mU} / \mathrm{mL}$, respectively. The absorption spectral change in the PDA vesicles was negligible when AChE or ACh was added (Figure S3).

The absorption spectra of the PDA vesicles $(50 \mu \mathrm{mol} / \mathrm{L})$ in the presence of $\mathrm{ACh}(40 \mu \mathrm{mol} / \mathrm{L})$ were measured after introducing different amounts of $\mathrm{AChE}$ and further incubation for different times. As anticipated, the absorption spectra varied after the addition of $\mathrm{AChE}$ and further incubation. Figure 5(A) shows the variation in the CR, which measures the absorption spectral change for the PDA vesicles as mentioned above, vs. the reaction time $(0-15 \mathrm{~min})$ in the presence of different concentrations of AChE. The degree of CR increase by prolonging the reaction time was clearly more significant when the concentration of AChE in the PDA vesicles solution was higher, as depicted in Figure 5(A). For example, the $\mathrm{CR}$ value increased rapidly and remained essentially unchanged after incubation for $\sim 6.0 \mathrm{~min}$ when the concentration of AChE reached $80.0 \mathrm{mU} / \mathrm{mL}$. Therefore, a colorimetric assay for AChE activity was established with the amine-terminated PDA vesicles. Moreover, an AChE concentration as low as $10.0 \mathrm{mU} / \mathrm{mL}$ can be assayed under the current conditions.

$\mathrm{ACh}$ is a central neurotransmitter and its hydrolysis catalyzed by AChE is an important process that regulates the neutral response system [40]. Clinical treatment of Alzheimer's disease is mainly based on AChE inhibitors [41]. Therefore, the development of a reliable assay method for measuring AChE activity and screening for AChE inhibitors is of significant importance. AChE activity and inhibition behaviors are traditionally monitored with absorption spectroscopy using the Ellman's reagent [42]. Fluorometric approaches with good sensitivity have been reported for screening AChE inhibitors [43-45]. Chemiluminescent probes are also available for AChE activity assays and inhibitor screening [46]. The current colorimetric assay for $\mathrm{AChE}$ and inhibitor screening has the advantages having a visible assay for AChE and inhibitor screening that is fast and easily-operated.

This convenient colorimetric assay for monitoring AChE activity with PDA vesicles was further explored as a potentially suitable assay for screening AChE inhibitors. Neostigmine, a well-known inhibitor for AChE [47], was selected as an example to demonstrate the application of the PDA vesicles in screening AChE inhibitors. The color of the PDA vesicles solution changed from blue to red after introducing $\mathrm{AChE}$ to the solution containing $\mathrm{ACh}$ as detailed above. However, the rate of color change slowed upon the addition of neostigmine to the vesicles solution. At
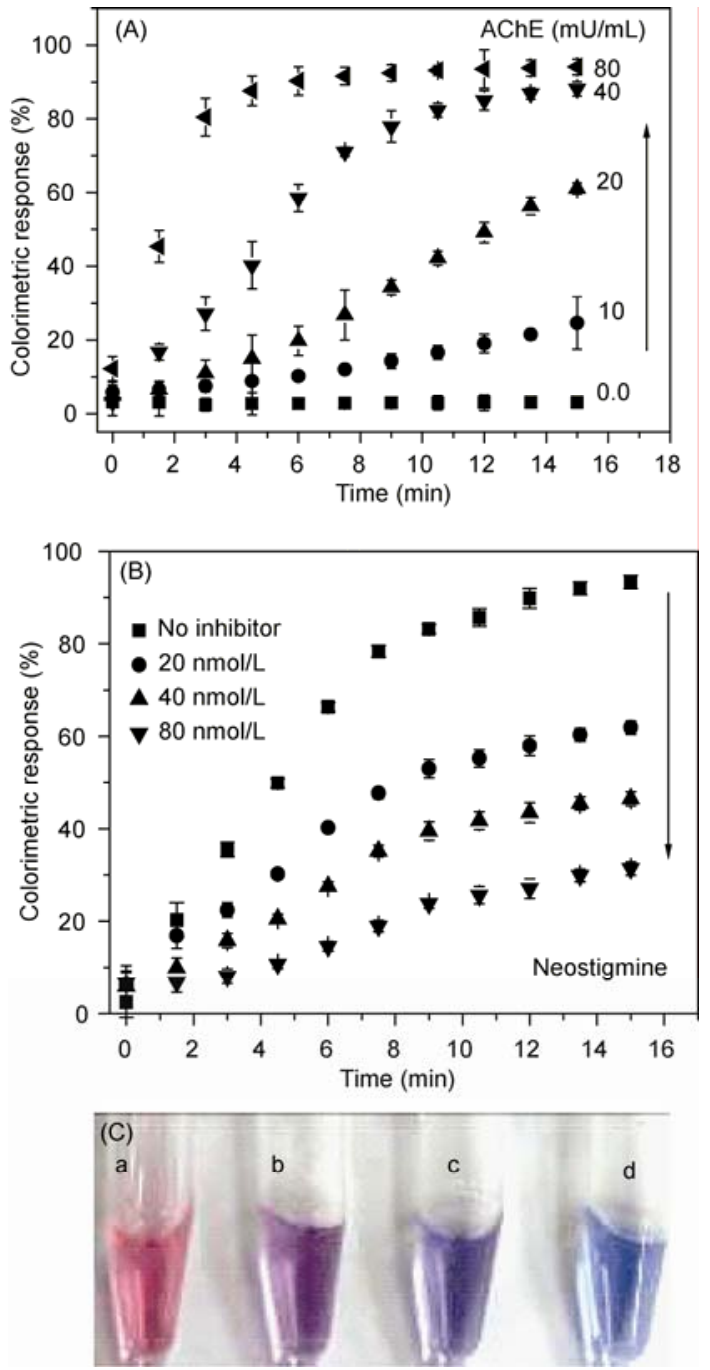

Figure 5 (A) Variation in the colorimetric response vs. the reaction time for the PDA vesicles solutions $(50 \mu \mathrm{mol} / \mathrm{L})$ containing acetylcholine (40 $\mu \mathrm{mol} / \mathrm{L})$ and different amounts of $\operatorname{AChE}(0,10,20,40$ and $80 \mathrm{mU} / \mathrm{mL})$; each solution was incubated for $15 \mathrm{~min}$ at $25^{\circ} \mathrm{C}$. (B) Variation in the colorimetric response $v s$. the reaction time for the PDA vesicles $(50 \mu \mathrm{mol} / \mathrm{L})$ containing acetylcholine $(40 \mu \mathrm{mol} / \mathrm{L})$, AChE $(40 \mathrm{mU})$ and different concentrations of neostigmine $(0,20,40$ and $80 \mathrm{nmol} / \mathrm{L})$; each solution was incubated for $15 \mathrm{~min}$ at $25^{\circ} \mathrm{C}$. (C) Photos of the PDA vesicles solutions (50 $\mu \mathrm{mol} / \mathrm{L})$ containing ACh $(40 \mu \mathrm{mol} / \mathrm{L}), \mathrm{AChE}(40 \mathrm{mU} / \mathrm{mL})$ and different amounts of neostigmine: a, 0; b, 20; c, 40; and d, $80 \mathrm{nmol} / \mathrm{L}$. Each solution was incubated for $15 \mathrm{~min}$ at $25^{\circ} \mathrm{C}$. All experiments were carried out in UHP water.

the highest neostigmine concentration examined the color of the vesicles solution remained essentially blue under the same conditions (Figure 5(C)). These results showed that neostigmine inhibits the activity of AChE and thus the hydrolysis of ACh into acetic acid is dramatically reduced. As a result of less acetic acid being produced, less absorption change is observed because the $\mathrm{pH}$ has not changed significantly. Therefore, it is not only possible to conveniently perform a colorimetric assay for AChE activity with the PDA vesicles and ACh, but it is also possible to screen for 
the activity of AChE inhibitors with the PDA vesicles.

Absorption spectra of the PDA vesicles containing ACh $(20 \mu \mathrm{mol} / \mathrm{L})$ and $\mathrm{AChE}(40 \mathrm{mU} / \mathrm{mL})$ in the presence of different concentrations of neostigmine $(0,20,40$ and 80 $\mathrm{nmol} / \mathrm{L}$ ) were measured after the solutions were incubated for different times to quantify the inhibition efficiency of neostigmine toward AChE. Clearly, variation in the CR vs. the reaction time became smoother after the addition of neostigmine compared with that in the absence of neostigmine (Figure 5(B)). For example, when the concentration of neostigmine in the solution reached $80.0 \mathrm{nmol} / \mathrm{L}$, the CR value was essentially unchanged even if the PDA vesicles solution was incubated for $15 \mathrm{~min}$. On the basis of the plot of the CR (measured after the incubation for $6 \mathrm{~min}$ ) vs. the concentration of neostigmine (Figure 6), the corresponding $\mathrm{IC}_{50}$ was estimated to be $31 \mathrm{nmol} / \mathrm{L}$. This value is different from the $\mathrm{IC}_{50}$ values reported before [47]. However, this difference can be accounted for because the $\mathrm{IC}_{50}$ values usually increase as the enzyme concentration increases.

\section{Conclusion}

In summary, a convenient colorimetric approach for the detection of glucose and a colorimetric assay for monitoring AChE activity were successfully established using amineterminated PDA vesicles. The colorimetric methods take advantage of the following features: (1) the amine- terminated PDA vesicles exhibit a color transition as the $\mathrm{pH}$ value of the solution decreases; (2) glucose can be oxidized to gluconic acid in the presence of GOx; and (3) AChE catalyzes the hydrolysis of acetylcholine into acetic acid. The "coupling" of the PDA vesicles with reactions catalyzed by particular enzymes offers a visual detection approach to assay for glucose and AChE with good selectivity and acceptable sensitivity. The detection limit of glucose is

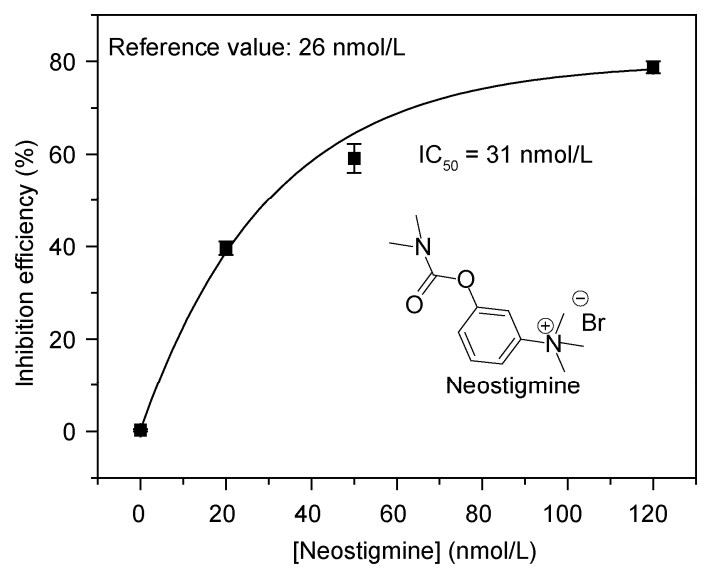

Figure 6 Inhibition efficiency of neostigmine toward AChE vs. the concentration of neostigmine. The data were obtained with the PDA vesicles (50 $\mu \mathrm{mol} / \mathrm{L})$, ACh $(40 \mu \mathrm{mol} / \mathrm{L})$ and $\mathrm{AChE}(40 \mathrm{mU} / \mathrm{mL})$ in the presence of different concentrations of neostigmine $(0,20,40,80 \mathrm{nmol} / \mathrm{L})$. about $2.5 \mu \mathrm{mol} / \mathrm{L}$, whereas the limit for measuring AChE activity is $\sim 10.0 \mathrm{mU} / \mathrm{mL}$. Moreover, the results clearly demonstrate the usefulness of this convenient assay for screening the potency of AChE inhibitors. Given its simplicity and easy operation, this method may be suitable for high-throughput screening of AChE inhibitors and other relevant drug discovery platforms.

The work was supported by the National Natural Science Foundation of China (21075126), the National Basic Research Program of China (2010CB933502).

1 Wegner G. Topochemical polymerization of monomers with conjugated triple bonds. Makromol Chem, 1972, 154: 35-48

2 Batchelder D N, Evans S D, Freeman T L, et al. Self-assembled monolayers containing polydiacetylenes. J Am Chem Soc, 1994, 116: 1050-1053

3 Kim T, Crooks R M, Tsen M, et al. Polymeric self-assembled monolayers. 2. Synthesis and characterization of self-assembled polydiacetylene mono- and multilayers. J Am Chem Soc, 1995, 117: 39633967

4 Okada S, Peng S, Spevak W, et al. Color and chromism of polydiacetylene vesicles. Acc Chem Res, 1998, 31: 229-239

5 Song J, Cisar J S, Bertozzi C R. Functional self-assembling bolaamphiphilic polydiacetylenes as colorimetric sensor scaffolds. J Am Chem Soc, 2004, 126: 8459-8465

6 Ahn D J, Chae E H, Lee G S, et al. Colorimetric reversibility of polydiacetylene supramolecules having enhanced hydrogen-bonding under thermal and pH stimuli. J Am Chem Soc, 2003, 125: 89768977

7 Song J, Cheng Q, Kopta S, et al. Modulating artificial membrane morphology: $\mathrm{pH}$-induced chromatic transition and nanostructural transformation of a bolaamphiphilic conjugated polymer from blue helical ribbons to red nanofibers. J Am Chem Soc, 2001, 123: 32053213

8 Cheng Q, Yamamoto M, Stevens R C. Amino acid terminated polydiacetylene lipid microstructures: morphology and chromatic transition. Langmuir, 2000,16: 5333-5342

9 Kew S J, Hall E H. pH response of carboxy-terminated colorimetric polydiacetylene vesicles. Anal Chem, 2006, 78: 2231-2238

10 Jonas U, Shah K, Norvez S, et al. Reversible color switching and unusual solution polymerization of hydrazide-modified diacetylene lipids. J Am Chem Soc, 1999, 121: 4580-4588

11 Yuan Z, Hanks T W. A reversible colorimetric and fluorescent polydiacetylene vesicle sensor platform. Polymer, 2008, 49: 5023-5026

12 Yuan Z, Lee C W, Lee S H. Reversible thermochromism in hydrogen-bonded polymers containing polydiacetylenes. Angew Chem Int Ed, 2004, 43: 4197-4200

13 You X, Chen X, Zou G, et al. Colorimetric response of azobenzene-terminated polydiacetylene vesicles under thermal and photic stimuli. Chem Phys Lett, 2009, 482: 129-133

14 Sun X, Chen T, Huang S, et al. UV-induced chromatism of polydiacetylenic assemblies. J Phys Chem B, 2010, 114: 2379-2382

15 Peng H, Sun X, Cai F, et al. Electrochromatic carbon nanotube/ polydiacetylene nanocomposite fibres. Nat Nanotechnol, 2009, 4: 738741

16 Cheng Q, Stevens R. Coupling of an induced fit enzyme to polydiacetylene thin films: Colorimetric detection of glucose. Adv Mater, 1997, 9: 481-483

17 Cheng Q, Peng T, Stevens R C. Signaling of escherichia coli enterotoxin on supramolecular redox bilayer vesicles. J Am Chem Soc, 1999, 121: 6767-6768

18 Toko K. Taste sensor. Sens Actuators B, 2000, 64: 205-215

19 Li Y, Ma B, Fan Y, et al. Electrochemical and Raman studies of the bio-interaction between escherichia coli and mannose in polydiacety- 
lene derivative supported on the self-assembled monolayers of octadecanethiol on gold electrode. Anal Chem, 2002, 74: 6349-6354

20 Sun C Y, Zhang Y, Fan Y, et al. Mannose-escherichia coli interactions in the presence of metal cations studied in vitro by colorimetric polydiacetylene/glycolipid liposomes. J Inorg Biochem, 2004, 98: 925-930

21 Kim J M, Lee Y B, Yang D H, et al. A Polydiacetylene-based fluorescent sensor chip. J Am Chem Soc, 2005, 127: 17580-17581

22 Kolusheva S, Zadmard R, Schrader T, et al. Color fingerprinting of proteins by calixarenes embedded in lipid/polydiacetylene vesicles. J Am Chem Soc, 2006, 128: 13592-13598

23 Chae S K, Park H, Yoon J, et al. Polydiacetylene supramolecules in electrospun microfibers: Fabrication, micropatterning, and sensor applications. Adv Mater, 2007, 19: 521-524

24 Ahn D J, Kim J M. Fluorogenic polydiacetylene supramolecules: Immobilization, micropatterning, and application to label-free chemosensors. Acc Chem Res, 2008, 41: 805-816

25 Yoon B, Lee S, Kim J M. Recent conceptual and technological advances in polydiacetylene-based supramolecular chemosensors. Chem Soc Rev, 2009, 38: 1958-1968

26 Jose D A, König B. Polydiacetylene vesicles functionalized weith $\mathrm{N}$-heterocyclic ligands for metal cation binding. Org Biomol Chem, 2010, 8: 655-662

27 Kim J M, Ji E K, Woo S M, et al. Immobilized polydiacetylene vesicles on solid substrates for use as chemosensors. Adv Mater, 2003, 15: 1118-1122

28 Park E Y, Kim J W, Ahn D J, et al. Polydiciacetylene supramolecular system that emits red, green, and blue fluorescence. Macromol Rapid Commun, 2007, 28: 171-175

29 Jung Y K, Kim T W, Kim J, et al. Universal colorimetric detection of nucleic acids based on polydiacetylene (PDA) liposomes. Adv Funct Mater, 2008, 9999: 1-8

30 Lee J, Kim H J, Kim J S. Polydiacetylene liposome arrays for selective potassium detection. J Am Chem Soc, 2008, 130: 5010-5011

31 Napoli A, Boerakker M J, Tirelli N, et al. Glucose-oxidase based self-destructing polymeric vesicles. Langmuir, 2004, 20: 3487-3491

32 O'Farrell H K, Chattopadhyay S K, Brown H D. Calorimetry of cholinesterase activity in serum. Clin Chem, 1977, 23: 1853-1856

33 Charych D, Nagy J O, Spevak W, et al. Direct colorimetric detection of a receptor-ligand interaction by a polymerized bilayer assembly. Science, 1993, 261: 585-588

34 Ballerstadt R, Schultz J S. A fluorescence affinity hollow fiber sensor for continuous transdermal glucose monitoring. Anal Chem, 2000,
72: 4185-4192

35 Ge X, Tolosa L, Rao G. Dual-labeled glucose binding protein for ratiometric measurements of glucose. Anal Chem, 2004, 76: 14031410

36 Lam W, Chu L H, Wong C L, et al. A surface plasmon resonance system for the measurement of glucose in aqueous solution. Sens Acuators B, 2005, 105: 138-143

37 Nakamura H, Mogi Y, Akimoto T, et al. An enzyme-chromogenic surface plasmon resonance biosensor probe for hydrogen peroxide determination using a modified Trinder's reagent. Biosens Bioelectron, 2008, 24: 455-460

38 Pasta M, Mantia F L, Cui Y. A new approach to glucose sensing at gold electrodes. Electrochem Commun, 2010, 12: 1407-1410

39 Nenkova R, Ivanova D, Vladimirova J, et al. New amperometric glucose biosensor based on cross-linking of glucose oxidase on silica gel/multiwalled carbon nanotubes/polyacrylonitrile nanocomposite film. Sens Actuators B, 2010, 148: 59-65

40 Whitehouse P J, Price D L, Struble R G, et al. Alzheimers-disease and senile dementia-loss of neurons in the basal forebrain. Science, 1982, 215: 1237-1239

41 Miao Y Q, He N Y, Zhu J J. History and new developments of assays for cholinesterase activity and inhibition. Chem Rev, 2010, 110: 5216-5234

42 Ellman G L, Courtney K D, Andres V, et al. A new and rapid colorimetric determination of acetylcholinesterase activity. Biochem Pharmacol, 1961, 7: 88-90

43 Maeda $\mathrm{H}$, Mastuno $\mathrm{H}$, Ushida $\mathrm{M}$, et al. 2,4-Dinitrobenzenesulfonyl fluoresceins as fluorescent alternatives to Ellman's reagent in thiolquantification enzyme assays. Angew Chem Int Ed, 2005, 44: 29222925

44 Feng F D, Tang Y L, Wang S. Continuous fluorometric assays for acetylcholinesterase activity and inhibition with conjugated polyelectrolytes. Angew Chem Int Ed, 2007, 46: 7882-7886

45 Peng L H, Zhang G X, Zhang D Q, et al. A fluorescence "turn-on" ensemble for acetylcholinesterase activity assay and inhibitor screening. Org Lett, 2009, 11: 4014-4017

46 Godoy S, Leca-Bouvier B, Boullanger P, et al. Electrochemiluminescent detection of acetylcholine using acetylcholinesterase immobilized in a biomimetic Langmuir-Blodgett nanostructure. Sens Actuators B, 2005, 107: 82-87

47 Kishibayashi N, Ishii A, Karasawa A. Inhibitory effects of KW-5092, a novel gastroprokinetic agent on the activity of acetylcholinesterase in Guinea Pig Ileum. Jpn J Pharmacol, 1994, 66: 397-403

Open Access This article is distributed under the terms of the Creative Commons Attribution License which permits any use, distribution, and reproduction in any medium, provided the original author(s) and source are credited.

\section{Supporting Information}

Figure S1 Variation of the colorimetric re-sponse (CR) vs. the reaction time for the PDA-vesicles and glucose (40.0 $\mu$ mol/L) in the presence of different concentrations of GOx $(0.0,0.01,0.05,0.08$ and $0.10 \mathrm{mg} / \mathrm{mL})$.

Figure S2 (A)Absorption spectra of PDA vesicles containing only glucose (a), only GOx (b) and those after glucose was oxidized in the presence of GOx for $20 \mathrm{~min}$ at $25^{\circ} \mathrm{C}$ (c); the solution under investigation was composed of PDA vesicles $(50.0 \mu \mathrm{mol} / \mathrm{L}), \mathrm{glucose}(40.0 \mu \mathrm{mol} / \mathrm{L})$, and $\mathrm{GOx}(0.08 \mathrm{mg} / \mathrm{mL})$.

Figure S3 Absorption spectra of PDA vesicles containing only acetylcholine (black), only AChE (green) and that after acetylcholine was hydrolyzed in the presence of $\mathrm{AChE}(40.0 \mathrm{mU} / \mathrm{mL})$ for $20.0 \mathrm{~min}$ at $25^{\circ} \mathrm{C}$ (red); the solution under investigation was composed of PDA vesicles (50.0 $\left.\mu \mathrm{mol} / \mathrm{L}\right)$, acetylcholine $(40.0 \mu \mathrm{mol} / \mathrm{L})$, and $\mathrm{AChE}(40.0 \mathrm{mU} / \mathrm{mL})$

The supporting information is available online at csb.scichina.com and www.springerlink.com. The supporting materials are published as submitted, without typesetting or editing. The responsibility for scientific accuracy and content remains entirely with the authors. 